\title{
O processo de ensino e aprendizagem de Matemática para alunos surdos: uma revisão sistemática
}

\author{
Mathematics teaching and the learning process \\ by deaf students: a systematic review
}

\author{
Renata da Silva Dessbesel ${ }^{1}$ \\ https://orcid.org/0000-0002-2781-2397 \\ Sani de Carvalho Rutz da Silva ${ }^{1}$ \\ https://orcid.org/0000-0002-1548-5739 \\ Elsa Midori Shimazaki ${ }^{2}$ \\ https://orcid.org/0000-0002-2225-5667
}

\begin{abstract}
Resumo: Neste estudo objetivamos investigar as intervenções didático-pedagógicas na Educação Básica para o ensino de matemática a alunos surdos. Utilizamos uma revisão sistemática descritiva da literatura contida em artigos, dissertações e teses disponíveis nas bases de dados Scientific Electronic Library Online e Instituto Brasileiro de Informação em Ciência e Tecnologia nos anos de 2013 a 2017. Usamos os descritores surdos, matemática e ensino, e localizamos 616 pesquisas. Após a seleção, consideramos 16 estudos como amostra final da revisão. Podemos inferir que os estudos apresentaram múltiplas possibilidades, como experiências em ambientes computacionais, cenários investigativos, uso de recursos como materiais didáticos, todos flexíveis e com planejamentos na aplicação. Ao pensarmos a educação matemática para surdos, foco deste estudo, observamos avanços nas pesquisas, tais como as contribuições que os trabalhos analisados trouxeram para a área. Todavia, alertamos para a necessidade de realizar mais pesquisas que respondam às necessidades da efetivação do processo de ensino e aprendizagem no interior das escolas.

Palavras-chave: Ensino de matemática. Educação de surdos. Escola inclusiva. Revisão bibliográfica.
\end{abstract}

\begin{abstract}
This study aims to investigate the didactic and pedagogical intervention at Basic Education for math teaching to deaf students. It used a systematic descriptive review from literature articles, dissertations, and theses from Scientific Electronic Library Online and Instituto Brasileiro de Informação em Ciência e Tecnologia databases from 2013 to 2017. The descriptors deaf, mathematics and teaching were used, and 616 studies were found. After the search, 16 studies were selected as a final sample of the review. It can be inferred that the studies present multiple possibilities, such as computing environments experiences, investigative scenarios, use of didactic resources as educational materials, all of them with pre-established design and flexible application. When thinking about math education for the deaf, there is an advance at the research level as the analyzed works contribute to the area. However, we emphasize the need for more research that could answer the needs of the teaching and learning process on effectiveness inside the schools.
\end{abstract}

Keywords: Mathematics teaching. Education for deaf. Inclusive school. Bibliographic search.

\footnotetext{
${ }^{1}$ Universidade Tecnológica Federal do Paraná (UTFPR), Programa de Pós-Graduação em Ensino de Ciência e Tecnologia (PPGECT), Ponta Grossa, PR, Brasil. E-mail: < renatadessbesel@utfpr.edu.br>.

${ }^{2}$ Universidade Estadual de Maringá (UEM), Programa de Pós-Graduação em Educação, Maringá, PR, Brasil.
} 


\section{Introdução}

Nos últimos anos, muitas são as discussões em torno da Educação Especial, especificamente quando o tema é a inclusão de alunos com necessidades especiais na sala de aula do ensino regular. Pesquisadores (DOZIAT, 2013; MATOS; MENDES, 2015; OLIVEIRA; MANZINI, 2016) assinalam que avanços importantes foram conquistados, como a Sala de Recursos Multifuncionais e o apoio especializado, mas que ainda precisamos de mais investimento na qualificação dos professores e na estrutura física das escolas, bem como de profissionais habilitados para o acompanhamento dos alunos e a efetivação das políticas públicas no interior das escolas.

Diante desses desafios, existe a compreensão da Educação Especial direcionada à inclusão dos alunos, garantindo condições de acesso e permanência nas escolas. A Política Nacional de Educação Especial na Perspectiva da Educação Inclusiva aborda esse tema de modo que todos os alunos possam aprender juntos no mesmo espaço educacional, com a finalidade de participação, aprendizagem e continuidade da Educação Infantil ao Ensino Superior (BRASIL, 2014). A inclusão parte do princípio de que a educação é direito de todos e essencial para o desenvolvimento de uma sociedade justa e igualitária.

Neste texto, nossa atenção direciona-se à Educação de Surdos, sujeitos que por muitos anos tiveram negada a possibilidade de aprender a língua de sinais para comunicação, sendo obrigados a desenvolver a oralidade e fazer leitura labial (GESSER, 2009). O Decreto 5626 (BRASIL, 2005) propiciou aos surdos a garantia da educação bilíngue e/ou ensino em salas regulares com a presença de um intérprete, assegurando também o atendimento especializado no turno inverso.

A partir desse Decreto, entram em cena o espaço escolar e a língua de sinais, que não é universal, mas é reconhecida linguisticamente, porque apresenta gramática própria e estrutura em todos os níveis (fonológico, morfológico, sintático e semântico). Além disso, manifesta características tais como a criatividade (possibilidade de combinar unidades), flexibilidade (é versátil, podemos utilizar todos os tempos verbais), descontinuidade (diferenças mímicas como a configuração de mãos e a contextualização mudam o sentido da palavra) e arbitrariedade (regras específicas). No Brasil, temos a Libras (Língua Brasileira de Sinais) (GESSER, 2009).

O papel da linguagem e sua relação com o desenvolvimento cognitivo nos levam a entender possibilidades para o ensino. Nesse sentido, Gesser (2009), apoiado nos estudos de Vygotsky, assinala que os surdos não apresentam problemas cognitivos de aprendizagem, mas sim barreiras na escolarização. Nessa direção, Moura (2013, p. 20) acentua que é “[...] pela linguagem que o indivíduo estabelece sua identidade e se configura como único nas suas particularidades", mostrando a necessidade de comunicação, de troca de experiências de interações com o meio para que esses alunos possam compreender o mundo à sua volta e constituir-se como sujeitos sociais.

As crianças surdas, do ponto de vista psicológico e pedagógico, devem ser compreendidas no mesmo paradigma que as crianças ouvintes, com a especificidade de que seu desenvolvimento ocorre de forma diferente, pois recorrerão a outros instrumentos de mediação, como os gestos e sinais (VYGOSTKI, 1997). Este autor explica que na internalização dos instrumentos e signos, produzidos por meio da interação com o meio, é que acontece o desenvolvimento cognitivo. Assim, a linguagem é responsável pela mediação entre o indivíduo e a cultura, ainda 
O processo de ensino e aprendizagem de Matemática por alunos surdos: ...

mais que as funções psicológicas superiores, socialmente formadas, são culturalmente transmitidas por meio da linguagem.

Vygotski (1997) afirma ainda que a linguagem e o pensamento surgem da necessidade de comunicação, que são resultantes das adaptações necessárias da vida. Em sua acepção, a escola constitui-se como espaço para aprender a língua, e praticamente todas as atividades estão ao alcance dos surdos, e isso abre uma oportunidade de um ensino em conjunto com as pessoas ouvintes. Góes (2012) pontua que a deficiência não restringe as possibilidades, mas que existem possibilidades diferentes, e o planejamento da sala de aula deve dedicar-se ao que a criança potencialmente pode aprender.

De acordo com Vygotsky (1998), a aprendizagem inicia antes de a criança ingressar à escola. $\mathrm{O}$ autor exemplifica que as crianças, em seu cotidiano, têm contato com medidas, quantidades, operações de adição, ou seja, a aritmética já está presente em diversas situações. Dessa forma, a criança aprende com outra pessoa, nas mais diferentes interações com o objeto de conhecimento. Nesse sentido, um conceito importante é a Zona de Desenvolvimento Proximal (ZDP), entendida por Vygotsky (1998) como a distância entre a determinação das soluções de problemas de forma independente, o que a criança já sabe e o que ela é potencialmente capaz de aprender com a mediação de um adulto. É na ZDP que o professor atua para transformar os conhecimentos que o aluno já tem em conhecimento científico.

O ensino de matemática para alunos surdos perpassa por todas essas questões e merece atenção quando o pensamos em relação à linguagem, uma vez que estamos acrescentando uma nova - a linguagem matemática, com todos seus postulados, teoremas e demonstrações. No tocante à linguagem da matemática, ainda há muitos termos que não possuem um sinal em LIBRAS, situações que exigem, muitas vezes, que os intérpretes negociem um novo sinal com os surdos, ou usem a datilologia para traduzir um determinado conceito que está sendo ensinado pelo professor. Nesse sentido, Borges e Nogueira (2016) acrescentam que a língua de sinais ainda está em construção, que pode haver situações em que o intérprete de LIBRAS não tem domínio da matemática, configurando situações de dificuldades para os surdos.

Os estudos no campo da Matemática têm entusiasmado pesquisadores (COUTINHO; CARVALHO, 2016; MOURA, 2015; RODRIGUES; GELLER, 2016; SALES; PENTEADO; MOURA, 2015), que desenvolvem estudos com conteúdos de matemática contemplados no Ensino Fundamental e destacam a língua de sinais como necessária no processo de ensino e aprendizagem, pois é por meio dela que acontecem as trocas, a negociação de significados e a linguagem é compartilhada. Assim sendo, a Libras atua como mediadora dos processos cognitivos. Nessa perspectiva, Moura (2013, p. 15) contribui: “A LIBRAS desempenha todas as funções de uma língua e, como tal, poderia ser usada para cumprir o papel que a linguagem oral tem na criança ouvinte".

Frizzarini e Nogueira (2014) acrescentam que a língua de sinais também apresenta características específicas no que se refere à linguagem matemática, alicerçadas no fundamento da representação. Em sua pesquisa sobre o desenvolvimento algébrico dos surdos, as autoras enfatizam que esses alunos precisam fazer uso de LIBRAS para generalizar e abstrair as representações algébricas; logo, devem explorar as vantagens que a língua lhes fornece, desprendendo-se do uso exagerado dos algoritmos.

As abordagens para a matemática em sala de aula precisam ir além dos processos metódicos e da memorização de fórmulas; anseia-se por um ensino contextualizado, diverso, 
que extrapole a escola, e no qual possam ser abordados assuntos sociais, políticos e ambientais. A Base Nacional Comum Curricular (BNCC) (BRASIL, 2017) propõe que os alunos sejam capazes de resolver problemas nos diferentes cenários, utilizando instrumentos da matemática para aplicar conceitos e procedimentos para obter soluções e saber interpretá-las. Coutinho e Carvalho (2016) contribuem com estudos acerca do letramento propondo práticas de leitura em aulas de matemática. Pontuamos que, no ambiente de inclusão, isso possibilita refletir sobre a constituição da identidade surda.

Como estratégias que contemplam e apresentam resultados satisfatórios do ensino da disciplina de Matemática para estudantes surdos, alguns autores (ARNOLDO; RAMOS; THOMA, 2013; BRET'TAS, 2015; FERNANDES; HEALY, 2013, 2016) recorrem em suas pesquisas à Teoria Histórico-Cultural e utilizam o conceito de mediação, em que a Libras desempenha o papel de mediação e colabora na internalização dos conceitos da disciplina de Matemática.

Os alunos surdos demonstram certa facilidade em realizar cálculos e as dificuldades aparecem quando lhes são apresentados textos de linguagem específica da matemática, uma vez que não são expressos em Libras (COSTA; SILVEIRA, 2014). Nessa lógica, Nogueira, Andrade e Zanquetta (2011) refletem sobre a formação efetiva dos conceitos, e questionam se os alunos surdos aprenderam ou apenas memorizaram os procedimentos e os algoritmos do cálculo. Tanto os estudos de Costa e Silveira (2014) quanto os de Nogueira, Andrade e Zanquetta (2011) concluem que não é somente uma tradução de uma língua para outra, por meio do intérprete, mas que essa interpretação envolve questões culturais, domínio da linguagem matemática e posiciona o professor como mediador das relações, propondo atividades que permitam que o aluno seja sujeito de sua aprendizagem. Fernandez-Víader e Fuentes (2013) asseveram que os erros cometidos pelos alunos surdos nas operações de adição e subtração podem estar relacionados à falta de pré-requisitos de matemática devido à falha conceitual que acontece no ensino dessa disciplina para esses estudantes, aliada à exiguidade de experiências educacionais anteriores à escola.

O ensino de matemática passou por muitas adaptações e transformações em seu currículo, mas principalmente em sua perspectiva metodológica, que amplia os recursos e instrumentos utilizados em sala de aula, com o uso de materiais didáticos manipuláveis, representações visuais e ambientes tecnológicos. Nesse sentido, quando pensamos a Educação Especial, essa realidade também deve estar presente, e algumas pesquisas nos mostram bons resultados (FERNANDES; HEALY, 2016; KIPPER; OLIVEIRA; THOMA, 2015; ROCHA, 2014), pois permitiram que os alunos explorassem estruturas visuais, e relacionassem a comunicação visual dos conhecimentos matemáticos e a língua de sinais. Entretanto, apesar de todos os esforços e das barreiras de comunicação, o principal desafio dos professores de matemática "é encontrar contextos nos quais as interpretações dos objetivos da atividade estimulem os alunos a se apropriarem de tais ferramentas” (FERNANDES; HEALY, 2013, p. 367).

A inclusão dos alunos surdos na sala de aula pode ser contemplada de duas maneiras: por meio do ensino regular e pelo acompanhamento do intérprete ou em escolas bilíngues. Ambas apresentam vantagens e desafios, e a questão central é que o aluno alcançará sucesso no ensino de matemática se houver respeito à sua diversidade linguística e meios que oportunizem e valorizem suas capacidades, seja pela visualização, pelo uso da língua oral ou sinalizada. Enfim, meios que tenham um planejamento direcionado às suas potencialidades.

Diante desse cenário, no presente estudo tivemos como objetivo investigar as intervenções didático-pedagógicas na Educação Básica para o ensino de matemática aos alunos 
O processo de ensino e aprendizagem de Matemática por alunos surdos: ...

surdos por meio de uma revisão sistemática descritiva da literatura de artigos, dissertações e teses indexados sobre o tema. A partir das análises apresentamos um panorama desses estudos nos últimos cinco anos.

\section{Método}

Este estudo decorre de uma pesquisa de revisão sistemática, definida por Sampaio e Mancini (2007) como uma forma de pesquisa que faz uso de dados da literatura sobre um determinado tema, constituindo um conjunto de estudos que podem expor pontos convergentes e/ou coincidentes e lacunas existentes para pesquisas futuras. A revisão foi norteada por sete etapas, a saber: construção do protocolo, definição da pergunta, busca dos estudos, seleção dos estudos, avaliação crítica, coleta dos dados e síntese dos dados (GALVÃO; SAWADA; TREVIZAN, 2004), as quais conduziram o trabalho de pesquisa e as análises. Elencamos os procedimentos adotados em nosso estudo.

a) Construção do protocolo: fase de planejamento da revisão sistemática, em que definimos a pergunta, as bases de pesquisa, os critérios de seleção dos estudos, os procedimentos de busca, a avaliação e a análise dos estudos;

b) Definição da pergunta: como base para o estudo, nos orientamos pela pergunta inicial: "Quais intervenções didático-pedagógicas têm sido utilizadas na Educação Básica para o ensino da matemática aos alunos surdos?”;

c) A busca dos estudos: as bases de dados escolhidas foram a Scientific Electronic Library Online (SciELO), que reúne periódicos científicos brasileiros e a Biblioteca Digital Brasileira de Teses e Dissertações (BDTD), que pertence ao Instituto Brasileiro de Informação em Ciência e Tecnologia (IBICT) e agrega as pesquisas defendidas no Brasil e por brasileiros no exterior. Como palavras-chave para a busca, utilizamos "Surdos" e "Ensino" e "Surdos" e "Matemática";

d) Seleção dos estudos: após a busca nas bases, foi preciso definir os critérios de inclusão e exclusão das pesquisas. Como critérios de inclusão, selecionamos: (a) publicações no período de 2013 a 2017; (b) estudos empíricos que apresentam e avaliam métodos/metodologias em sala de aula para o ensino de matemática; e, (c) estudos realizados com alunos da Educação Básica. Como critérios de exclusão: (a) artigos, teses e dissertações que tratam de revisão de literatura e ensaios teóricos; (b) não disponíveis na íntegra; (c) investigações de situações de sala de aula com ensino de matemática, cujo foco é o professor e/ou intérprete; e, (d) investigações de situações em outras áreas do conhecimento;

e) Avaliação crítica: realizamos a avaliação crítica dos estudos conforme o objetivo central da revisão, analisando as possibilidades de intervenções didático-pedagógicas para o ensino de matemática com alunos surdos inclusos na Educação Básica nos últimos cinco anos. Esse período é considerado por entendermos que a inclusão de estudantes surdos na escola é recente na perspectiva de pensarmos o processo de ensino e aprendizagem desses estudantes;

f) Coleta de dados: encontramos 616 trabalhos entre artigos, dissertações e teses, sendo 95 no SciELO e 521 no IBICT. Depois de salvos em meio digital, iniciamos o procedimento de seleção da amostra da revisão sistemática. Aplicamos o primeiro critério de inclusão relacionado aos estudos de 2013 a 2017 e resultaram em 49 no SciELO e 253 no IBICT. Para os critérios 
de exclusão ${ }^{3}$ (a, c, d) e inclusão ${ }^{4}$ (c), realizamos a leitura dos títulos e do resumo das pesquisas, resultando em 7 trabalhos no SciELO e 23 no IBICT (Figura 1). Foi necessário excluir os estudos duplicados, restando 6 no SciELO e 10 no IBICT, os quais foram lidos em sua totalidade e analisados. Os resultados serão apresentados no próximo tópico.

Figura 1. Fluxograma da coleta de dados

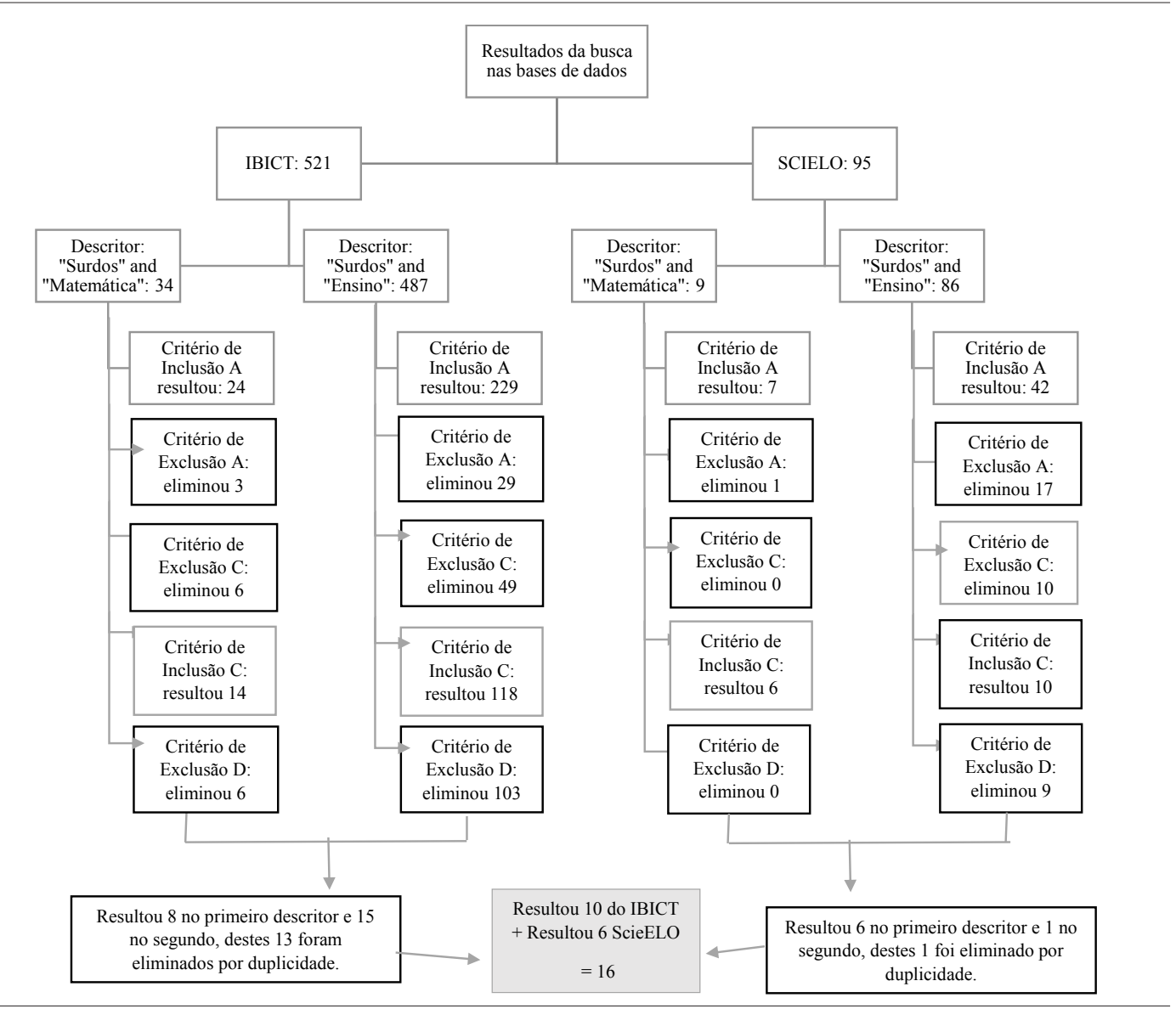

Fonte: elaborada pelas autoras.

g) Sintese dos dados: trata-se de uma revisão sistemática qualitativa, cujos dados obtidos são analisados descritivamente quanto ao ano de publicação, objetivo, participantes do estudo, aspectos metodológicos e principais resultados.

A seguir, discorremos sobre os resultados do estudo de revisão.

\footnotetext{
${ }^{3} \mathrm{O}$ critério de exclusão (b) não foi citado no fluxograma, pois todos os estudos estavam disponíveis na íntegra.

${ }^{4} \mathrm{O}$ critério de inclusão (b) foi considerado simultaneamente com o critério de exclusão (a).
} 
O processo de ensino e aprendizagem de Matemática por alunos surdos: ...

\section{Resultados e discussões}

Conforme Doziat (2013), a inclusão como proposta de implementação mundial, trouxe muitos desafios à sociedade, em especial à escola, que precisou se adaptar física e pedagogicamente para receber todos os alunos, com atenção especial às suas diferenças. A escola que se propõe inclusiva deve garantir aos seus discentes o que já está definido na legislação: um ensino de qualidade para todos, com oportunidades iguais de desenvolvimento. Borges e Nogueira (2016) enunciam que em relação aos alunos surdos, esbarra-se em uma questão de comunicação, a linguagem oral, que afeta diretamente todas as propostas metodológicas nas diferentes disciplinas, em particular na matemática, já que é preciso abarcar sua linguagem, constituída de termos muito específicos e que nem sempre apresentam uma tradução para Libras.

As publicações analisadas têm maior produção no ano de 2015, em que há um aumento de 40\% em relação ao ano anterior. Quanto às publicações nos periódicos, 83,3\% possuem Qualis A1 e 16,7\% Qualis A2 na classificação de periódicos da Capes, quadriênio 2013-2016. No que tange às teses e dissertações, a maior concentração foi de dissertações em programas de Mestrado Profissional em Ciências e/ ou Matemática (60\%), enquanto à localização, 60\% se concentram em Programas de Pós-Graduação em universidades do sudeste brasileiro.

No Quadro 1 apresentamos os estudos selecionados, os objetivos e o conteúdo de matemática desenvolvido. De acordo com a BNCC (BRASIL, 2017), os conteúdos de matemática estão organizados em cinco unidades temáticas: Números, Álgebra, Geometria, Grandezas e Medidas, Probabilidade e Estatística. Em nossa análise observamos que 50\% das pesquisas estão concentradas na unidade temática "Números", que abrange o pensamento numérico, quantidades, construção da noção de número, operações fundamentais, equivalência e ordem, proporcionalidade, resolução de problemas com número naturais, inteiros e racionais. Tratase de uma etapa da educação matemática no Ensino Fundamental na qual a criança inicia seu contato formal com os números, e na qual a linguagem matemática está rodeada de situações que podem ser exploradas com o lúdico e que servirão de base aos conteúdos que o sucedem. Nessa direção, Rodrigues e Geller (2016, p. 127) pontuam que esse momento pode trazer muitos desafios, pois a criança também está entrando em contato com a língua de sinais: “os mesmos dedos da mão que são utilizados pelo aluno como apoio para realizar contagens também são empregados na sinalização dos números em Libras".

No Quadro 1 estão organizados os trabalhos analisados, resultado da revisão sistemática, com os autores, título, objetivo da pesquisa e conteúdo de matemática envolvida na pesquisa empírica.

Em relação aos objetivos dos trabalhos analisados, foram agrupados em quatro categorias: (a) como acontece a inclusão do aluno surdo nas aulas de Matemática e a mediação por meio da língua de sinais (18,7\%); (b) análise da construção do conhecimento e das estratégias de resolução dos conteúdos de matemática por alunos surdos (43,8\%); (c) investigação da interação entre os elementos gestuais ou da visualização nas práticas de matemática em Libras (18,7\%), e; (d) análise das contribuições de um material pedagógico ou de recursos digitais para o ensino de matemática a alunos surdos (18,8\%). Dois objetivos se reportam à língua de sinais e confirmam sua importância para o processo de aprendizagem dos alunos surdos. Rodrigues e Geller (2016) enunciam que, muitas vezes, o primeiro contato com a língua de sinais acontece simultaneamente à fase em que os alunos chegam a escola. Se compararmos 
os objetivos aos conteúdos desenvolvidos nos estudos, podemos inferir que a maioria foram experiências desenvolvidas nesse momento da vida escolar, ou seja, esses alunos estão aprendendo Libras e elaborando, operando e resolvendo situações que envolvem números.

Quadro 1. Apresentação dos estudos quanto ao objetivo e conteúdo de matemática

\begin{tabular}{|c|c|c|c|c|}
\hline $\mathbf{N}^{\mathbf{o}}$ & Autor/Ano & Título & Objetivo & $\begin{array}{c}\text { Conteúdo de } \\
\text { matemática }\end{array}$ \\
\hline 1 & $\begin{array}{l}\text { FERNANDES, } \\
\text { S. H. A. A.; } \\
\text { HEALY, L. } \\
(2016)\end{array}$ & $\begin{array}{l}\text { A emergência } \\
\text { do pensamento } \\
\text { algébrico nas } \\
\text { atividades de } \\
\text { aprendizes surdos. }\end{array}$ & $\begin{array}{l}\text { Compreender como pessoas surdas } \\
\text { usuárias da Língua Brasileira de Sinais } \\
\text { (Libras) constroem significados } \\
\text { matemáticos para a generalização de } \\
\text { padrões. }\end{array}$ & $\begin{array}{l}\text { - Funções; } \\
\text { - Sequências. }\end{array}$ \\
\hline 2 & $\begin{array}{l}\text { SALES, E. R.; } \\
\text { PENTEADO; } \\
\text { M. G.; } \\
\text { MOURA, A. } \\
\text { Q. (2015) }\end{array}$ & $\begin{array}{l}\text { A negociação de } \\
\text { sinais em Libras } \\
\text { como possibilidade } \\
\text { de ensino e de } \\
\text { aprendizagem de } \\
\text { geometria. }\end{array}$ & $\begin{array}{l}\text { Analisar as habilidades e os } \\
\text { conhecimentos do grupo de alunos } \\
\text { surdos acerca de geometria; trabalhar } \\
\text { por meio da língua de sinais as noções } \\
\text { de ponto, reta, plano, ângulos, figuras } \\
\text { planas, e classificar as figuras planas } \\
\text { (quadrado, triângulo, círculos e outros } \\
\text { polígonos). }\end{array}$ & $\begin{array}{l}\text { Geometria: } \\
\text { figuras } \\
\text { planas e suas } \\
\text { propriedades. }\end{array}$ \\
\hline 3 & $\begin{array}{l}\text { BRETTAS, K. } \\
\text { P. (2015) }\end{array}$ & $\begin{array}{l}\text { A inclusão } \\
\text { matemática de um } \\
\text { aluno surdo na rede } \\
\text { municipal de Juiz } \\
\text { de Fora mediada } \\
\text { por um professor } \\
\text { colaborativo surdo } \\
\text { de Libras em } \\
\text { bidocência. }\end{array}$ & $\begin{array}{l}\text { Buscar na escola, espaço rico em } \\
\text { diversidade, a resposta à nossa } \\
\text { indagação inicial de como é possível } \\
\text { fazer a inclusão de aluno surdo em aulas } \\
\text { de matemáticas? }\end{array}$ & $\begin{array}{l}\text { - Quantidades; } \\
\text { - Contagem. }\end{array}$ \\
\hline 4 & $\begin{array}{l}\text { PEIXOTO, J. } \\
\text { L. B. (2015) }\end{array}$ & $\begin{array}{l}\text { Análise dos } \\
\text { esquemas de surdos } \\
\text { sinalizadores } \\
\text { associados aos } \\
\text { significados da } \\
\text { divisão. }\end{array}$ & $\begin{array}{l}\text { Compreender de que forma as ações } \\
\text { viso-gestual-somáticas em Libras } \\
\text { influenciam os esquemas mobilizados } \\
\text { por alunos surdos sinalizadores diante } \\
\text { de situações que abordem diferentes } \\
\text { significados da divisão. }\end{array}$ & $\begin{array}{l}\text { Divisão: medidas: } \\
\text { comparação } \\
\text { multiplicativa e } \\
\text { combinatória. }\end{array}$ \\
\hline 5 & $\begin{array}{l}\text { ALVES, F. B. } \\
(2015)\end{array}$ & $\begin{array}{l}\text { Raciocínio } \\
\text { qualitativo e } \\
\text { desenvolvimento de } \\
\text { raciocínio hipotético- } \\
\text { dedutivo: uma } \\
\text { proposta para alunos } \\
\text { surdos. }\end{array}$ & $\begin{array}{l}\text { - Apresentar proposta de curso de } \\
\text { ensino de ciências apoiada por modelos } \\
\text { qualitativos para alunos surdos em um } \\
\text { contexto bilíngue: LIBRAS / português } \\
\text { escrito; } \\
\text { - Proposta de um curso baseado no uso } \\
\text { de modelagem qualitativa para aquisição } \\
\text { de conceitos científicos por alunos } \\
\text { surdos dentro de um contexto bilíngue. }\end{array}$ & Raciocínio lógico. \\
\hline
\end{tabular}


O processo de ensino e aprendizagem de Matemática por alunos surdos: ...

Quadro 1. continuação

\begin{tabular}{|c|c|c|c|c|}
\hline $\mathbf{N}^{\mathbf{o}}$ & Autor/Ano & Título & Objetivo & $\begin{array}{c}\text { Conteúdo de } \\
\text { matemática }\end{array}$ \\
\hline 6 & $\begin{array}{l}\text { COUTINHO, } \\
\text { M. D. M. C. } \\
(2015)\end{array}$ & $\begin{array}{l}\text { A constituição } \\
\text { de saberes num } \\
\text { contexto de } \\
\text { educação bilíngue } \\
\text { para surdos em } \\
\text { aulas de matemática } \\
\text { numa perspectiva de } \\
\text { letramento. }\end{array}$ & $\begin{array}{l}\text { Investigar a aprendizagem que se } \\
\text { constitui numa prática bilíngue de } \\
\text { letramento em aulas de matemática } \\
\text { com alunos surdos, a partir de uma } \\
\text { visão de surdez enquanto construção } \\
\text { sociocultural e histórica. }\end{array}$ & $\begin{array}{l}\text { - Frações; } \\
\text { - Números } \\
\text { decimais com } \\
\text { sistemas de } \\
\text { medidas; } \\
\text { - Porcentagem e } \\
\text { proporções. }\end{array}$ \\
\hline 7 & $\begin{array}{l}\text { MOURA, A. } \\
\text { Q. (2015) }\end{array}$ & $\begin{array}{l}\text { Educação } \\
\text { matemática e } \\
\text { crianças surdas: } \\
\text { explorando } \\
\text { possibilidades em } \\
\text { um cenário para } \\
\text { investigação. }\end{array}$ & $\begin{array}{l}\text { Estabelecer uma compreensão sobre o } \\
\text { engajamento de crianças surdas em uma } \\
\text { proposta de cenários para investigação. }\end{array}$ & $\begin{array}{l}\text { - Pensamento } \\
\text { numérico; } \\
\text { - Ordenação } \\
\text { numérica. }\end{array}$ \\
\hline 8 & $\begin{array}{l}\text { PEIXOTO, J. } \\
(2015)\end{array}$ & $\begin{array}{l}\text { Gestos, sinais } \\
\text { e esquemas de } \\
\text { aprendizes surdos na } \\
\text { multiplicação. }\end{array}$ & $\begin{array}{l}\text { Investigar a interação entre elementos } \\
\text { gestuais e esquemas mobilizados por } \\
\text { esses sujeitos nas práticas matemáticas } \\
\text { em Libras. }\end{array}$ & Multiplicação. \\
\hline 9 & $\begin{array}{l}\text { BARBOSA, H. } \\
\text { H. (2014) }\end{array}$ & $\begin{array}{l}\text { Conceitos } \\
\text { matemáticos iniciais } \\
\text { e linguagem: um } \\
\text { estudo comparativo } \\
\text { entre crianças surdas } \\
\text { e ouvintes. }\end{array}$ & $\begin{array}{l}\text { Investigar o desempenho das crianças } \\
\text { surdas e ouvintes de idades entre } 5 \text { e } 6 \\
\text { anos (educação infantil) por meio de } \\
\text { tarefas experimentais que compreendam } \\
\text { vários aspectos cognitivos ligados à } \\
\text { conceituação quantitativo-numérica. }\end{array}$ & Contagem. \\
\hline 10 & $\begin{array}{l}\text { CALDEIRA, } \\
\text { V. L. A. (2014) }\end{array}$ & $\begin{array}{l}\text { Ensino de geometria } \\
\text { para alunos surdos: } \\
\text { um estudo com } \\
\text { apoio digital ao } \\
\text { analógico o o ciclo } \\
\text { da experiência } \\
\text { Kellyana. }\end{array}$ & $\begin{array}{l}\text { Analisar as contribuições dos recursos } \\
\text { digitais em uma interlocução com } \\
\text { os analógicos na aprendizagem de } \\
\text { conteúdos de geometria. }\end{array}$ & $\begin{array}{l}\text { Geometria: } \\
\text { polígonos. }\end{array}$ \\
\hline 11 & $\begin{array}{l}\text { ROCHA, F. B. } \\
\text { M. (2014) }\end{array}$ & $\begin{array}{l}\text { Ensinando } \\
\text { geometria espacial } \\
\text { para alunas surdas de } \\
\text { uma escola pública } \\
\text { de Belo Horizonte } \\
\text { (MG): um estudo } \\
\text { fundamentado na } \\
\text { perspectiva histórico- } \\
\text { cultural. }\end{array}$ & $\begin{array}{l}\text { Observar como as alunas trabalham } \\
\text { durante a intervenção, com a inserção } \\
\text { de objetos manipulativos (massinha } \\
\text { de modelar, canudinhos, gominhas } \\
\text { etc.), em resposta às situações didáticas } \\
\text { propostas com a intenção de ensinar } \\
\text { alguns conceitos de geometria espacial. }\end{array}$ & $\begin{array}{l}\text { Geometria } \\
\text { espacial. }\end{array}$ \\
\hline
\end{tabular}


Quadro 1. continuação

\begin{tabular}{|c|c|c|c|c|}
\hline $\mathbf{N}^{\mathbf{o}}$ & Autor/Ano & Título & Objetivo & $\begin{array}{l}\text { Conteúdo de } \\
\text { matemática }\end{array}$ \\
\hline 12 & $\begin{array}{l}\text { PEREIRA, P. } \\
\text { V. (2014) }\end{array}$ & $\begin{array}{l}\text { A surdez no } \\
\text { ambiente escolar: } \\
\text { um estudo das } \\
\text { representações } \\
\text { sociais de } \\
\text { professores de } \\
\text { matemática, } \\
\text { intérpretes e alunos. }\end{array}$ & $\begin{array}{l}\text { Compreender como o aluno surdo } \\
\text { compreende os conceitos matemáticos, } \\
\text { quais são suas habilidades em relação } \\
\text { a um aluno ouvinte, e quais fatores } \\
\text { interferem neste processo de ensino e } \\
\text { aprendizagem. }\end{array}$ & Logaritmo. \\
\hline 13 & $\begin{array}{l}\text { CORREA, A. } \\
\text { M. P. (2013) }\end{array}$ & $\begin{array}{l}\text { A divisão por alunos } \\
\text { surdos: ideias, } \\
\text { representações } \\
\text { e ferramentas } \\
\text { matemáticas. }\end{array}$ & $\begin{array}{l}\text { Contribuir nos processos de ensino e da } \\
\text { aprendizagem da matemática por alunos } \\
\text { surdos, mais especificamente, buscar } \\
\text { compreender como os alunos surdos } \\
\text { constroem suas estratégias na resolução } \\
\text { de atividades que envolvem divisão. }\end{array}$ & Divisão. \\
\hline 14 & $\begin{array}{l}\text { SALES, E. R. } \\
(2013)\end{array}$ & $\begin{array}{l}\text { A visualização } \\
\text { no ensino de } \\
\text { matemática: uma } \\
\text { experiência com } \\
\text { alunos surdos. }\end{array}$ & $\begin{array}{l}\text { Investigar como os alunos surdos } \\
\text { se desenvolvem em um plano de } \\
\text { intervenção baseado em atividades } \\
\text { que privilegiam os aspectos visuais dos } \\
\text { conceitos matemáticos. }\end{array}$ & $\begin{array}{l}\text { Geometria: } \\
\text { figuras planas. }\end{array}$ \\
\hline 15 & $\begin{array}{l}\text { FERNÁN- } \\
\text { DEZ-VIA- } \\
\text { DER, M. P.; } \\
\text { FUENTES, M. } \\
(2013)\end{array}$ & $\begin{array}{l}\text { Observando } \\
\text { estratégias e } \\
\text { buscando soluções: } \\
\text { a resolução de } \\
\text { operações por } \\
\text { adolescentes surdos. }\end{array}$ & $\begin{array}{l}\text { Descrever as estratégias de resolução } \\
\text { das operações de adição e subtração: o } \\
\text { que constitui o fundamento, para que } \\
\text { seja possível elaborar recomendações } \\
\text { sobre o ensino de matemática para } \\
\text { crianças e adolescentes surdos. }\end{array}$ & $\begin{array}{l}\text { Adição e } \\
\text { subtração. }\end{array}$ \\
\hline 16 & $\begin{array}{l}\text { ARNOLDO } \\
\text { JR., H.; } \\
\text { RAMOS, M. } \\
\text { O.; THOMA, } \\
\text { A. S. (2013) }\end{array}$ & $\begin{array}{l}\text { O uso do multiplano } \\
\text { por alunos surdos e } \\
\text { o desenvolvimento } \\
\text { do pensamento } \\
\text { geométrico. }\end{array}$ & $\begin{array}{l}\text { Analisar as contribuições desse material } \\
\text { para a aprendizagem de geometria e } \\
\text { para o desenvolvimento do pensamento } \\
\text { geométrico desses alunos. }\end{array}$ & $\begin{array}{l}\text { Geometria: } \\
\text { figuras planas. }\end{array}$ \\
\hline
\end{tabular}

Fonte: elaborado pelas autoras a partir de dados da pesquisa.

O uso de materiais didático-pedagógicos, assim como o uso de tecnologias para o ensino de matemática abordado nos trabalhos analisados, vem ao encontro das tendências atuais. Arnoldo Jr., Ramos e Thoma (2013) fizeram uso do Multiplano em sua pesquisa e concluíram que esse recurso possibilitou transformar os conceitos abstratos em concretos com a utilização de signos. Rocha (2014), utilizando materiais como massinha de modelar e papel-cartão para a construção dos sólidos geométricos, régua e compasso para a planificação destes no papel, constatou que os alunos desenvolveram mais autonomia e que as dificuldades foram vencidas com o auxílio dos recursos. Os recursos podiam ser visitados sempre que surgissem dúvidas nas atividades propostas, atuando como mediadores na construção do conhecimento e agindo na zona de desenvolvimento proximal dos alunos. 
O processo de ensino e aprendizagem de Matemática por alunos surdos: ...

Em relação à metodologia utilizada no ambiente da sala de aula no Quadro 2, trazemos uma síntese das pesquisas analisadas.

Os sujeitos envolvidos nas pesquisas encontradas são todos alunos surdos da Educação Básica, um critério para a seleção deste estudo. A maioria pertence a escolas públicas, $62,5 \%$ a escolas regulares de ensino, ou seja, instituições que, em teoria, praticam a inclusão, como é possível verificarmos nas pesquisas (itens 8, 11, 12 e 14 do Quadro 2). Nas pesquisas é relatado que as escolas possuem uma proposta de inclusão, apoio de intérpretes de Libras para acompanhamento das aulas e algumas (itens 8, 12 e 14 do Quadro 2) possuem Atendimento Educacional Especializado na Sala de Recursos Multifuncionais. Citamos uma pesquisadora, que alega que nesse “[...] espaço, notamos a possibilidade de uma maior flexibilidade na organização dos conteúdos, horários e efetividade na colaboração da pesquisa com a escola, sem interferir muito no andamento de suas atividades" (PEIXOTO, 2015b, p. 104). Sales (2013) também faz referência a esse espaço trazendo que o apoio pedagógico é focado nos conteúdos curriculares de matemática, português, história, geografia e ciências, e realizado por uma docente das séries iniciais e uma intérprete de Libras.

Quadro 2. Síntese dos procedimentos metodológicos dos estudos

\begin{tabular}{|c|c|c|c|c|c|}
\hline $\mathbf{N}^{\circ} *$ & Sujeitos & $\begin{array}{l}\text { Escola onde } \\
\text { a pesquisa foi } \\
\text { desenvolvida }\end{array}$ & $\begin{array}{l}\text { Instrumentos } \\
\text { de coleta }\end{array}$ & $\begin{array}{l}\text { Abordagem } \\
\text { metodológica }\end{array}$ & Análise dos dados \\
\hline 1 & $\begin{array}{l}6 \text { alunos } \\
\text { surdos } / 9^{\circ} \\
\text { ano E. F.*** } \\
/ \text { entre } 18 \text { e } \\
31 \text { anos }\end{array}$ & $\begin{array}{l}\text { Escola pública } \\
\text { regular do } \\
\text { Estado de São } \\
\text { Paulo }\end{array}$ & Filmagem & $\begin{array}{l}\text { Metodologia do } \\
\text { Design Experi- } \\
\text { ment }\end{array}$ & $\begin{array}{l}\text { Perspectiva de Radford como } \\
\text { uma das condições para o pen- } \\
\text { samento algébrico. }\end{array}$ \\
\hline 2 & $\begin{array}{l}8 \text { alunos } \\
\text { surdos / } 5^{\circ} \\
\text { ano E. F. / } \\
\text { entre } 10 \text { e } \\
13 \text { anos }\end{array}$ & $\begin{array}{l}\text { Escola pública } \\
\text { regular do } \\
\text { Estado de São } \\
\text { Paulo }\end{array}$ & $\begin{array}{l}\text { Filmagem, } \\
\text { notas diário } \\
\text { de campo, } \\
\text { produções dos } \\
\text { alunos. }\end{array}$ & $\begin{array}{l}\text { Não especifi- } \\
\text { cada }\end{array}$ & $\begin{array}{l}\text { Orientada pelas pesquisas } \\
\text { quanto à visualização e a de- } \\
\text { pendência de alunos surdos à } \\
\text { modalidade visual. }\end{array}$ \\
\hline 3 & $\begin{array}{l}1 \text { aluno } \\
\text { surdo / } 3^{\circ} \\
\text { ano E. F. / } \\
8 \text { anos }\end{array}$ & $\begin{array}{l}\text { Escola pública } \\
\text { de educação } \\
\text { especial do } \\
\text { Estado de } \\
\text { Minas Gerais }\end{array}$ & $\begin{array}{l}\text { Observação in } \\
\text { loco, entrevistas } \\
\text { e filmagem. }\end{array}$ & Estudo de caso & $\begin{array}{l}\text { Perspectiva de Vygotsky para } \\
\text { interpretar a compreensão ma- } \\
\text { temática dos sujeitos surdos da } \\
\text { pesquisa: aluno e professor. }\end{array}$ \\
\hline 4 & $\begin{array}{l}5 \text { alunos } \\
\text { surdos / } 1^{\circ} \\
\text { ano E. M. / } \\
\text { entre18 e } 22 \\
\text { anos }\end{array}$ & $\begin{array}{l}\text { Escola pública } \\
\text { regular do Es- } \\
\text { tado da Bahia }\end{array}$ & $\begin{array}{l}\text { Caderno de } \\
\text { notas do } \\
\text { pesquisador } \\
\text { para o registro } \\
\text { dos esquemas } \\
\text { dos estudan- } \\
\text { tes frente } \\
\text { às situações } \\
\text {-problema, e } \\
\text { filmagens. }\end{array}$ & $\begin{array}{l}\text { Pesquisa explo- } \\
\text { ratória, qualita- } \\
\text { tiva e pesquisa } \\
\text { de campo }\end{array}$ & $\begin{array}{l}\text { Interpretação por meio da } \\
\text { análise microgenética. }\end{array}$ \\
\hline
\end{tabular}


Quadro 2. continuação

\begin{tabular}{|c|c|c|c|c|c|}
\hline $\mathbf{N}^{\circ *}$ & Sujeitos & $\begin{array}{c}\text { Escola onde } \\
\text { a pesquisa foi } \\
\text { desenvolvida }\end{array}$ & $\begin{array}{l}\text { Instrumentos } \\
\text { de coleta }\end{array}$ & $\begin{array}{l}\text { Abordagem } \\
\text { metodológica }\end{array}$ & Análise dos dados \\
\hline 5 & $\begin{array}{l}12 \text { alunos } \\
\text { surdos / } 2^{\circ} \\
\text { e } 3^{\circ} \text { anos E. } \\
\text { F. / idade } \\
\text { não infor- } \\
\text { mada }\end{array}$ & $\begin{array}{l}\text { Escola pública } \\
\text { regular do Dis- } \\
\text { trito Federal }\end{array}$ & $\begin{array}{l}\text { Observações, } \\
\text { questionários, } \\
\text { entrevistas, } \\
\text { análise de } \\
\text { exercícios, e } \\
\text { gravador. }\end{array}$ & Estudo de caso & $\begin{array}{l}\text { Análise de conteúdo proposta } \\
\text { por Bardin. }\end{array}$ \\
\hline 6 & $\begin{array}{l}12 \text { alunos } \\
\text { surdos } / 7^{\circ} \\
\text { ano E. F. / } \\
\text { entre } 14 \text { e } \\
18 \text { anos }\end{array}$ & $\begin{array}{l}\text { Escola pública } \\
\text { de educação de } \\
\text { surdos do RJ }\end{array}$ & $\begin{array}{l}\text { Filmagens das } \\
\text { aulas, entrevis- } \\
\text { tas e registros } \\
\text { em diário da } \\
\text { pesquisadora, } \\
\text { e pesquisa } \\
\text { documental } \\
\text { em arquivos. }\end{array}$ & $\begin{array}{l}\text { Qualitativa de } \\
\text { campo }\end{array}$ & $\begin{array}{l}\text { Organizada a partir de três } \\
\text { situações: a aprendizagem na } \\
\text { perspectiva de letramento, a } \\
\text { mediação do assistente educa- } \\
\text { cional como educador e como } \\
\text { cidadão surdo, e o papel da } \\
\text { Libras e da língua Portuguesa } \\
\text { em um contexto de educação } \\
\text { bilíngue para surdos. }\end{array}$ \\
\hline 7 & $\begin{array}{l}4 \text { alunos } \\
\text { surdos / E. } \\
\text { F. / entre } 7 \\
\text { e } 9 \text { anos }\end{array}$ & $\begin{array}{l}\text { Instituição de } \\
\text { reabilitação } \\
\text { de pessoas } \\
\text { deficientes do } \\
\text { Estado de São } \\
\text { Paulo }\end{array}$ & $\begin{array}{l}\text { Caderno } \\
\text { de campo, } \\
\text { filmagens e } \\
\text { entrevista. }\end{array}$ & Estudo de caso & $\begin{array}{l}\text { Fundamentada em três eixos: o } \\
\text { aceite ou não para participação } \\
\text { da pesquisa, aos atos dialógi- } \\
\text { cos e aos riscos e obstáculos } \\
\text { presentes no processo. }\end{array}$ \\
\hline 8 & $\begin{array}{l}3 \text { alunos } \\
\text { surdos } / 7^{\circ} \\
\text { ano E. F. / } \\
\text { entre } 19 \text { e } \\
24 \text { anos }\end{array}$ & $\begin{array}{l}\text { Escola pública } \\
\text { regular do Es- } \\
\text { tado da Bahia }\end{array}$ & $\begin{array}{l}\text { Filmagem, } \\
\text { entrevistas. }\end{array}$ & Estudo de caso & $\begin{array}{l}\text { Conceito de esquema de Verg- } \\
\text { naud e da tipologia dos gestos } \\
\text { de McNeill. }\end{array}$ \\
\hline 9 & $\begin{array}{l}11 \text { alunos } \\
\text { surdos / } 2^{\circ} \\
\text { ano E. F. / } \\
\text { média de } 6 \\
\text { anos }\end{array}$ & $\begin{array}{l}\text { Escola pública } \\
\text { regular do Es- } \\
\text { tado de Santa } \\
\text { Catarina }\end{array}$ & $\begin{array}{l}\text { Entrevis- } \\
\text { tas clínicas } \\
\text { experimentais, } \\
\text { filmagens das } \\
\text { aulas. }\end{array}$ & $\begin{array}{l}\text { Metodologia } \\
\text { experimental }\end{array}$ & $\begin{array}{l}\text { Organizada quantitativamente } \\
\text { por meio do teste ANOVA e } \\
\text { qualitativamente por meio da } \\
\text { codificação das respostas. }\end{array}$ \\
\hline 10 & $\begin{array}{l}5 \text { alunos } \\
\text { surdos / } 8^{\circ} \\
\text { ano E. F. / } \\
\text { entre } 18 \text { e } \\
35 \text { anos }\end{array}$ & $\begin{array}{l}\text { Escola pública } \\
\text { de audioco- } \\
\text { municação } \\
\text { do Estado da } \\
\text { Paraíba }\end{array}$ & $\begin{array}{l}\text { Diários de } \\
\text { campo e } \\
\text { filmagem. }\end{array}$ & Estudo de caso & $\begin{array}{l}\text { Por meio do ciclo da experiên- } \\
\text { cia Kellyana. }\end{array}$ \\
\hline 11 & $\begin{array}{l}4 \text { alunos } \\
\text { surdos / } 9^{\circ} \\
\text { ano E. F. / } \\
\text { entre } 14 \text { e } \\
18 \text { anos }\end{array}$ & $\begin{array}{l}\text { Escola pública } \\
\text { regular do Es- } \\
\text { tado de Minas } \\
\text { Gerais }\end{array}$ & $\begin{array}{l}\text { Diário de } \\
\text { campo, entre- } \\
\text { vistas semies- } \\
\text { truturadas, } \\
\text { questionário e } \\
\text { gravações em } \\
\text { vídeo. }\end{array}$ & $\begin{array}{l}\text { Estudo quali- } \\
\text { tativo }\end{array}$ & $\begin{array}{l}\text { Constituída descritivamente } \\
\text { e interpretativamente, para } \\
\text { compreensão do processo e } \\
\text { da busca do significado que as } \\
\text { pessoas dão para as coisas. }\end{array}$ \\
\hline
\end{tabular}


O processo de ensino e aprendizagem de Matemática por alunos surdos: ...

Quadro 2. continuação

\begin{tabular}{|c|c|c|c|c|c|}
\hline $\mathbf{N}^{\circ *}$ & Sujeitos & $\begin{array}{l}\text { Escola onde } \\
\text { a pesquisa foi } \\
\text { desenvolvida }\end{array}$ & $\begin{array}{c}\text { Instrumentos } \\
\text { de coleta }\end{array}$ & $\begin{array}{l}\text { Abordagem } \\
\text { metodológica }\end{array}$ & Análise dos dados \\
\hline 12 & \begin{tabular}{|l|}
2 alunos \\
surdos / $1^{\circ}$ \\
ano E. M. \\
/ Idade não \\
informada \\
\end{tabular} & $\begin{array}{l}\text { Escola pública } \\
\text { regular do Es- } \\
\text { tado de Mato } \\
\text { Grosso do Sul }\end{array}$ & Entrevistas & Qualitativa & Análise do discurso. \\
\hline 13 & $\begin{array}{l}5 \text { alunos } \\
\text { surdos } / 6^{\circ} \\
\text { e } 7^{\circ} \text { anos E. } \\
\text { F. / entre } 16 \\
\text { e } 18 \text { anos }\end{array}$ & $\begin{array}{l}\text { Escola pública } \\
\text { de educação } \\
\text { de surdos do } \\
\text { Estado do Rio } \\
\text { de Janeiro }\end{array}$ & $\begin{array}{l}\text { Registros } \\
\text { produzidos } \\
\text { pelos alunos e } \\
\text { filmagens. }\end{array}$ & $\begin{array}{l}\text { Pesquisa quali- } \\
\text { tativa }\end{array}$ & $\begin{array}{l}\text { Análise das atividades em } \\
\text { grupos, de acordo com os } \\
\text { esquemas de ação necessários } \\
\text { à resolução dos problemas de } \\
\text { divisão, e em subcategorias } \\
\text { quanto à representação gráfica. }\end{array}$ \\
\hline 14 & $\begin{array}{l}8 \text { alunos } \\
\text { surdos / } 5^{\circ} \\
\text { ano E. F. / } \\
\text { entre } 10 \text { e } \\
13 \text { anos }\end{array}$ & $\begin{array}{l}\text { Escola pública } \\
\text { regular do } \\
\text { Estado de São } \\
\text { Paulo }\end{array}$ & $\begin{array}{l}\text { Caderno } \\
\text { de campo, } \\
\text { filmagens, } \\
\text { entrevistas e } \\
\text { documentos } \\
\text { escritos. }\end{array}$ & $\begin{array}{l}\text { Natureza explo- } \\
\text { ratória e descri- } \\
\text { tiva e de caráter } \\
\text { qualitativo. }\end{array}$ & $\begin{array}{l}\text { Quanto à determinação de } \\
\text { sinais em Libras para as formas } \\
\text { geométricas, a matemática } \\
\text { emergindo e o reconhecendo } \\
\text { formas geométricas. }\end{array}$ \\
\hline 15 & $\begin{array}{l}7 \text { alunos } \\
\text { surdos / } \\
\text { NC** / } \\
\text { entre } 12 \text { e } \\
15 \text { anos }\end{array}$ & $\begin{array}{l}\text { Escola regular } \\
\text { de Barcelona, } \\
\text { Espanha. }\end{array}$ & $\begin{array}{l}\text { Observação } \\
\text { participante, } \\
\text { filmagem, } \\
\text { registros pro- } \\
\text { duzidos por } \\
\text { alunos. }\end{array}$ & $\begin{array}{l}\text { Não especifi- } \\
\text { cada }\end{array}$ & $\begin{array}{l}\text { Anotações produzidas pelos } \\
\text { alunos nos protocolos de } \\
\text { resolução. }\end{array}$ \\
\hline 16 & $\begin{array}{l}2 \text { alunos } \\
\text { surdos / E. } \\
\text { F. / entre } 18 \\
\text { e } 35 \text { anos }\end{array}$ & $\begin{array}{l}\text { Escola de sur- } \\
\text { dos do Estado } \\
\text { do Rio Grande } \\
\text { do Sul }\end{array}$ & Observação & Estudo de caso & $\begin{array}{l}\text { Teoria de Van Hiele para anali- } \\
\text { sar a evolução do pensamento } \\
\text { geométrico. Para entender as } \\
\text { relações sociointeracionistas foi } \\
\text { utilizado Vygotsky. }\end{array}$ \\
\hline
\end{tabular}

* O número corresponde exatamente ao mesmo autor do quadro 1 ; **NC não consta no estudo analisado;

*** E. F.: ensino fundamental; E. M.: ensino médio.

Fonte: elaborado pelas autoras a partir de dados da pesquisa.

A Sala de Recursos Multifuncionais (SRM) na Educação Especial é um espaço organizado com recursos e equipamentos disponíveis para atender os alunos com deficiência e transtornos globais de desenvolvimento. Também pretende fortalecer o processo de inclusão, porém muitas vezes acaba sendo utilizada por alunos com dificuldade de aprendizagem e comportamento, encaminhados pela professora da turma regular por motivos de falta de adaptação ou como uma forma de reforço escolar. Diante disso, é preciso atentar à definição dos papéis dos profissionais envolvidos para que não se descaracterize o objetivo do Atendimento Educacional Especializado (AEE) e da SRM (OLIVEIRA; MANZINI, 2016). 
Nas pesquisas analisadas verificamos que a escolarização e a relação com a idade dos alunos surdos são diversas, em um intervalo de 6 a 35 anos, em que 81,2\% destes estão no Ensino Fundamental $\left(1^{\circ}\right.$ ao $9^{\circ}$ ano), e ainda, que $43,7 \%$ não estão frequentando a escola na idade certa, ao considerarmos que o aluno inicia na escola aos 6 anos e a conclui aos 17 anos. Esse fato também foi observado na pesquisa de Fernández-Viader e Fuentes (2013), que constataram atraso dos estudantes surdos na apropriação dos conteúdos em matemática.

Quanto à questão metodológica dos estudos analisados, nem todas especificaram e descreveram os métodos utilizados. Dessa forma, observamos a ênfase no ponto de vista da abordagem do problema em pesquisas qualitativas, fato compreensível porque a maioria desenvolve atividades com um grupo pequeno de alunos e está preocupada em entender as construções e as formas de raciocínio que esses alunos desenvolvem em relação à Matemática, mediadas, na maioria dos casos, pela língua de sinais. Observamos que 37,5\% das pesquisas fazem referência a um estudo de caso, definido por Gil (2008, p. 57) como "o estudo de caso é caracterizado pelo estudo profundo e exaustivo de um ou de poucos objetos, de maneira a permitir o seu conhecimento amplo e detalhado, tarefa praticamente impossível mediante os outros tipos de delineamentos considerados".

Os instrumentos para a coleta de dados utilizados nas pesquisas analisadas são diversos. $87,5 \%$ utilizaram filmagem, considerando que a comunicação com os estudantes foi realizada por meio da língua de sinais ou visualmente e que as gravações em vídeo tornam-se importante aliadas, pois para a análise é possível fazer uma criteriosa investigação, voltando e avançando as imagens. $\mathrm{Na}$ análise dos resultados destes estudos houve preocupação em utilizar uma teoria e/ ou método que abrangesse as produções dos alunos, entre as quais Teoria Histórico-Cultural, a Análise de Conteúdo, a Análise do discurso, a Teoria de Van Hiele, e os Esquemas de Vergnaud.

Verificamos que nos estudos apresentados, a seção metodológica destacava os participantes, principalmente nas dissertações e teses, em que havia uma descrição sobre os sujeitos, assim como as questões sociais, o envolvimento da família, questões relacionadas ao ingresso na escola e o contato com a língua de sinais. No tocante aos métodos utilizados nesses estudos, estes se mostram diversificados, com destaque para a descrição da análise dos dados e com procedimentos pré-estabelecidos.

No Quadro 3 apresentamos os principais resultados dos estudos analisados. Optamos por agrupá-los em quatro categorias gerais em relação à língua de sinais, à matemática, aos recursos metodológicos e ao processo de ensino e aprendizagem. Na segunda coluna elencamos subcategorias dos principais resultados.

A maioria dos estudos faz referência à língua de sinais, especialmente à necessidade que surgiu em suas atividades de se criar novos sinais para determinados conteúdos que estavam sendo desenvolvidos; relataram também que a criação desses sinais com auxílio dos intérpretes e dos alunos, de modo a compartilhar significados, trouxe avanços no processo de aprendizagem. Pontuamos que a escola tem papel central nesse processo de aquisição da linguagem, principalmente quando os alunos surdos possuem pais ouvintes, pois é no ambiente escolar que acontecerão suas primeiras experiências, e espera-se que a língua de sinais seja ensinada como a primeira língua para a criança, de modo que ela possa pensar, agir, decidir e organizar o mundo ao seu redor (MOURA, 2013).

Caldeira (2014) pondera que cabe aos professores buscar meios para conhecer e adquirir a língua de sinais, a fim de garantir uma relação de comunicação eficiente com seus alunos surdos. Além disso, devem conhecer também a comunidade surda e se possível se inserir nela, 
para que possam relacionar as argumentações com as experiências visuais deles, proporcionando o entendimento dos conteúdos. Sales (2013) defende uma escola em que os conteúdos possam ser abordados na língua de sinais, com docentes que interajam em Libras com eles. Essas premissas reforçam os resultados de uma Educação Bilíngue para a formação dos alunos surdos (COUTINHO, 2015; PEREIRA, 2014; SALES; PENTEADO; MOURA, 2015) permeada de experiências e trocas em relação à linguagem.

Quadro 3. Principais resultados dos estudos analisados

\begin{tabular}{|c|c|c|}
\hline $\begin{array}{l}\text { Categoria } \\
\text { de análise }\end{array}$ & Subcategorias - principais resultados & Estudos* \\
\hline \multirow{6}{*}{$\begin{array}{l}\text { (A) Em } \\
\text { relação a } \\
\text { língua de } \\
\text { sinais }\end{array}$} & $\begin{array}{l}\text { (i) Criação de sinais para estudos de conteúdos de matemática, e necessida- } \\
\text { de de ampliação do vocabulário de matemática em Libras. }\end{array}$ & $\begin{array}{l}1,2,10 \\
12,14,16\end{array}$ \\
\hline & $\begin{array}{l}\text { (ii) Processo de negociação e compartilhamento de sinais trouxe resultados } \\
\text { significativos na aprendizagem. }\end{array}$ & $\begin{array}{l}2,6,14, \\
16\end{array}$ \\
\hline & $\begin{array}{l}\text { iii) As crianças surdas que têm mais domínio da língua de sinais apresenta- } \\
\text { ram melhores resultados em relação à matemática. }\end{array}$ & 13,15 \\
\hline & iv) A Libras é um meio de construção do pensamento e do conhecimento. & $3,6,8,16$ \\
\hline & v) Predomínio dos registros escritos em relação à língua de sinais. & 4 \\
\hline & $\begin{array}{l}\text { vi) Educação bilíngue traz melhores resultados para o ensino de matemáti- } \\
\text { ca dos alunos surdos. }\end{array}$ & $2,6,12$ \\
\hline \multirow{6}{*}{$\begin{array}{l}\text { (B) Em } \\
\text { relação ao } \\
\text { ensino de } \\
\text { matemática }\end{array}$} & $\begin{array}{l}\text { i) Nas operações, os alunos ficaram muito dependentes da construção dos } \\
\text { algoritmos para resolução. }\end{array}$ & 8,13 \\
\hline & $\begin{array}{l}\text { ii) Revelaram defasagens em relação ao domínio da matemática, conside- } \\
\text { rando idade-série. }\end{array}$ & $8,9,15$ \\
\hline & iii) As crianças surdas precisaram de mais tempo para resolução. & 6,9 \\
\hline & $\begin{array}{l}\text { iv) Dificuldades nas quatro operações fundamentais (adição, subtração, } \\
\text { multiplicação e divisão). }\end{array}$ & $\begin{array}{l}4,10,13 \\
15\end{array}$ \\
\hline & v) Demonstraram raciocínio lógico, mas faltou postura argumentativa. & 7 \\
\hline & vi) Dificuldades na interpretação das questões em língua portuguesa. & 5 \\
\hline \multirow{6}{*}{$\begin{array}{l}(\mathrm{C}) \\
\text { Em relação } \\
\text { aos recursos } \\
\text { metodoló- } \\
\text { gicos }\end{array}$} & $\begin{array}{l}\text { i) Ambiente computacional permitiu explorar as situações e resultou em } \\
\text { aprendizagem dos conceitos de matemática. }\end{array}$ & 1 \\
\hline & $\begin{array}{l}\text { ii) Multiplano possibilitou transpor a materialidade da representação algé- } \\
\text { brica. }\end{array}$ & 16 \\
\hline & iii) Uso de recursos variados facilitou o processo de ensino e aprendizagem. & $\begin{array}{l}10,11 \\
12,14\end{array}$ \\
\hline & iv) Os elementos visuais auxiliaram o processo de aprendizagem. & 12,16 \\
\hline & v) O uso de material interdisciplinar serviu como estímulo à aprendizagem & 5 \\
\hline & $\begin{array}{l}\text { vi) Cenários investigativos como ambiente propício para o ensino de mate- } \\
\text { mática para surdos. }\end{array}$ & 7 \\
\hline \multirow{3}{*}{$\begin{array}{l}\text { (D) } \\
\text { Em relação } \\
\text { ao processo } \\
\text { de ensino e } \\
\text { aprendiza- } \\
\text { gem }\end{array}$} & $\begin{array}{l}\text { i) Prática reflexiva mediada pelo corpo, signos e ferramentas trouxe mudan- } \\
\text { ça na construção do pensamento. }\end{array}$ & 1,16 \\
\hline & $\begin{array}{l}\text { ii) Afetividade como parte fundamental do processo de desenvolvimento } \\
\text { intelectual do aluno. }\end{array}$ & 3,11 \\
\hline & $\begin{array}{l}\text { iii) A zona de desenvolvimento proximal emergindo através da interação } \\
\text { entre os alunos. }\end{array}$ & 11 \\
\hline
\end{tabular}

*Os números desta coluna indicam os estudos conforme ordem que aparece no Quadro 1.

Fonte: elaborado pelas autoras a partir de dados da pesquisa. 
No âmbito da Matemática, nos estudos encontrados foram relatadas dificuldades dos alunos surdos em relação às quatro operações fundamentais (adição, subtração, multiplicação e divisão), ao mesmo tempo em que, na maioria das situações, o uso de estratégias metodológicas e a mediação com a língua de sinais trouxeram bons resultados no processo de ensino e aprendizagem. No relato de Caldeira (2014, p. 127), temos indícios da superação das dificuldades: "quanto aos cálculos, evidenciaram dificuldades nas operações básicas, todavia, para transpor esse entrave, buscaram apoio nas contagens usando riscos pequenos, para agrupar nas multiplicações, e separaram em grupos com quantidades iguais nas divisões". Ainda é preciso considerar que as defasagens podem estar associadas a questões sociais, à demora para manter contato com a Libras, e aos recursos disponíveis para a aprendizagem.

Os recursos e metodologias pensados para a sala de aula são diversos nos estudos encontrados. Atualmente, temos um rol de possibilidades a nosso alcance. Para o ensino de matemática são muitas as tendências metodológicas, desde o uso de materiais concretos como os jogos, os blocos lógicos, o Multiplan, a exploração da tecnologia disponível como o software Geogebra. Nesse sentido, os resultados dos estudos mostraram-se favoráveis ao uso de recursos, em vencer as barreiras de apenas uma aula expositiva com quadro e giz, para complementar com auxílio de instrumentos que podem ser mediadores na sala da aula. Pereira (2014), por exemplo, afirma que atividades lúdicas possibilitam o desenvolvimento de competências de representação, comunicação, investigação e auxiliam a contextualizar o ensino de matemática.

Entre seus papéis, cabe à educação introduzir a criança surda ou cega no meio social e criar uma compensação para as deficiências, de modo que essas crianças possam estabelecer formas de comunicação por meio de linguagens diferentes das demais pessoas ouvintes ou videntes (VYGOTSKI, 1997). Assim, estes são capazes de aprender, porém precisam de estímulos e encaminhamentos pedagógicos diferenciados. Observamos alguns traços de sua Teoria Sociocultural nas pesquisas analisadas, como a de Brettas (2015), que fez referência ao conceito de mediação e apontou que a Libras atuou como signo mediador, pois possibilitou a interação dos surdos no meio sociocultural em que estão inseridos. Como resultados, Fernandes e Healy (2016) relatam que os alunos foram guiados em uma atividade reflexiva mediada pelo corpo, signos e ferramentas, provocando alterações no pensamento algébrico conforme foram compreendendo os objetos matemáticos.

Diante dessas análises, observamos que a inclusão dos alunos surdos em sala de aula, ou a constituição de escolas bilíngues perpassa por muitas questões ainda a serem superadas, abrindo um campo rico e importante para os pesquisadores, educadores e pais que desejam estar envolvidos com o fortalecimento de uma sociedade inclusiva.

\section{Considerações finais}

A escola, ponto central de nossa discussão, é um espaço constituído de muitos desafios, rodeado de incertezas e diverso em relação aos sujeitos que a compõem. Aliado ao papel decisivo que tem na sociedade, como em muitos casos o único local de acesso ao conhecimento formal, esperamos que dela saiam sujeitos mais críticos, interativos, e capazes de resolver problemas e enfrentar situações em sua comunidade. É nesse cenário que buscamos entender a Educação Especial, garantida por lei, mas pouco efetivada em sua essência, pois ainda é capaz de separar ao invés de incluir as pessoas com deficiência. 
O processo de ensino e aprendizagem de Matemática por alunos surdos: ...

Nossa atenção é a Educação de Surdos, no entendimento de que esses sujeitos não possuem problemas cognitivos, como tipificados por muito tempo, mas que sua relação com o processo de ensino e aprendizagem está vinculada intrinsecamente com a linguagem. $\mathrm{O}$ aluno surdo organiza seus pensamentos por meio da linguagem, que nesse caso é a língua de sinais, e por meio dela é capaz de interagir na sociedade, de usar signos como auxílio para a elaboração do conhecimento científico.

Nosso objetivo de investigar as intervenções didático-pedagógicas na Educação Básica para o ensino de matemática aos alunos surdos, por meio de uma revisão sistemática descritiva da literatura de artigos, dissertações e teses foi efetivado. Podemos inferir que os estudos apresentaram múltiplas possibilidades, experiências em ambientes computacionais, cenários investigativos, uso de recursos concretos como construção de sólidos geométricos, materiais didáticos (por exemplo, o Multiplano), todos com planejamentos pré-estabelecidos e flexíveis na aplicação. Dessa forma, compreendemos que a aula de matemática, nos estudos analisados, supera as expectativas e caminha ao encontro de uma proposta de inclusão por possibilitar diferentes estratégias de aprendizagem.

O ensino de conteúdos de matemática atraentes, contextualizados e principalmente importantes para o aluno como sujeito social, desmistifica a ideia de uma disciplina difícil, em que só os melhores são capazes de aprender. Ao pensarmos a educação matemática para surdos, foco deste estudo, constatamos avanços nas pesquisas, como as contribuições que os trabalhos analisados trouxeram para a área, além das contribuições sociais, pois estas pesquisas permitem que outras escolas e outros professores possam utilizar suas metodologias desenvolvidas. Destacamos a importância da consolidação da língua de sinais nos espaços escolares inclusivos, trazendo contribuições para superar apenas a criação de leis e se efetivar como uma política pública capaz de consolidar espaços em que todos possam aprender juntos.

Devido à importância dessa temática, torna-se necessário o desenvolvimento de mais pesquisas, em especial no campo da matemática, que discutam a ampliação do vocabulário em Libras, que proponham espaços de formação inicial e continuada aos professores e que explorem outros campos da Matemática, como é o caso do ensino de funções, dos sistemas lineares, da probabilidade e da estatística, ainda ausentes nas propostas do ensino para surdos na etapa do Ensino Médio.

\section{Agradecimentos}

Registram-se aqui os melhores agradecimentos ao Conselho Nacional de Desenvolvimento Científico e Tecnológico (CNPq) pela concessão da Bolsa Produtividade em Pesquisa que muito tem auxiliado a realizar nossas pesquisas sobre Educação Inclusiva.

\section{Referências}

ALVES, F. B. Raciocínio qualitativo e desenvolvimento de raciocínio hipotéticodedutivo: uma proposta para alunos surdos. 2015. Dissertação (Mestrado Profissional em Ensino de Ciências) - Universidade de Brasília, Brasília, 2015.

ARNOLDO JR., H.; RAMOS, M. G.; THOMA, A. S. O uso do multiplano por alunos surdos e o desenvolvimento do pensamento geométrico. Cadernos Cedes, Campinas, v. 33, n. 91, p. 387-409, 2013. Disponível em: < https://doi.org/10.1590/S010132622013000300006>. Acesso em: 16 maio 2018. 
BARBOSA, H. H. Conceitos matemáticos iniciais e linguagem: um estudo comparativo entre crianças surdas e ouvintes. Educação e Pesquisa, São Paulo, v. 40, n. 1, p. 163-179, 2014. <https://doi.org/10.1590/S1517-97022014000100011>. Acesso em: 16 maio 2018.

BORGES, F. A.; NOGUEIRA, C. M. I. Das palavras aos sinais: o dito e o interpretado nas aulas de Matemática para alunos surdos inclusos. Perspectivas da Educação Matemática, Campo Grande, v. 9, n. 20, p. 479-500, 2016.

BRASIL. Ministério da Educação. Política nacional de educação especial na perspectiva da educação inclusiva. [Brasília, 2014]. Disponível em: <https:// tinyurl.com/jcgkrot>. Acesso em: 16 maio 2018.

BRASIL. Decreto $\mathbf{n}^{\mathbf{0}} \mathbf{5 . 6 2 6}$, de 22 de dezembro de 2005. Regulamenta a lei $\mathrm{n}^{\circ} \mathbf{1 0 . 4 3 6}$, de 24 de abril de 2002, que dispõe sobre a Língua Brasileira de Sinais - Libras, e o art. 18 da lei no 10.098, de 19 de dezembro de 2000. Brasília, 2005. Disponível em: < http:/ / www.planalto. gov.br/ccivil_03/_ato2004-2006/2005/decreto/d5626.htm>. Acesso em: 16 maio 2018.

BRASIL. Ministério da Educação. Base nacional comum curricular. Brasília, [2017]. Disponível em: < http://portal.mec.gov.br/conselho-nacional-de-educacao/base-nacionalcomum-curricular-bncc $>$. Acesso em: 16 maio 2018.

BRETTAAS, K. P. A inclusão matemática de um aluno surdo na rede municipal de Juiz de Fora mediada por um professor colaborativo surdo de Libras atuando em bidocência. 2015. Dissertação (Mestrado Profissional em Educação Matemática) Universidade Federal de Juiz de Fora, Juiz de Fora, 2015.

CALDEIRA, V. L. A. Ensino de geometria para alunos surdos: um estudo com apoio digital ao analógico e o ciclo da experiência kellyana. 2014. Dissertação (Mestrado Profissional em Ensino de Ciências e Matemática) - Universidade Estadual da Paraíba, João Pessoa, 2014.

CORREA, A. M. P. A divisão por alunos surdos: ideias, representações e ferramentas matemáticas. 2013. Dissertação (Mestrado Profissional em Educação Matemática) Universidade Federal de Juiz de Fora, Juiz de Fora, 2013.

COSTA, W. C. L.; SILVEIRA, M. R. A. Desafios da comunicação no ensino de matemática para alunos surdos. BoEM: boletim online de educação matemática, Joinville, v. 2, n. 2, p. 72-87, 2014.

COUTINHO, M. D. M. C. A constituição de saberes num contexto de educação bilíngue para surdos em aulas de matemática numa perspectiva de letramento. 2015. Tese (Doutorado em Educação) - Universidade Estadual de Campinas, Campinas, 2015.

COUTINHO, M. D. M. C.; CARVALHO, D. L. Educação matemática, surdez e letramentos: o processo de ensinar e aprender matemática mediado por duas línguas em contato. Revista Paranaense de Educação Matemática, Campo Mourão, v. 5, n. 9, p. 33-55, 2016.

DOZIAT, A. O profissional da inclusão escolar. Cadernos de Pesquisa, São Paulo, v. 43, n. 150, p. 986-1003, 2013. Disponível em: < https://doi.org/10.1590/S0100$15742013000300013>$. Acesso em: 16 maio 2018. 
O processo de ensino e aprendizagem de Matemática por alunos surdos: ...

FERNANDES, S. H. A. A.; HEALY, L. A emergência do pensamento algébrico nas atividades de aprendizes surdos. Ciência \& Educação, Bauru, v. 22, n. 1, p. 237-252, 2016. Disponível em: <https://doi.org/10.1590/1516-731320160010015>. Acesso em: 16 maio 2018.

FERNANDES, S. H. A.; HEALY, L. Expressando generalizações em libras: álgebra nas mãos de aprendizes surdos. Caderno Cedes, Campinas, v. 33, n. 91, p. 349-368, 2013. Disponível em: <https://doi.org/10.1590/S0101-32622013000300004>. Acesso em: 16 maio 2018.

FERNÁNDEZ-VIADER, M. P.; FUENTES, M. Observando estratégias e buscando soluções: a resolução de operações por adolescentes surdos. Cadernos Cedes, Campinas, v. 33, n. 91, p. 369-386, 2013. Disponível em: < https://doi.org/10.1590/S010132622013000300005>. Acesso em: 16 maio 2018.

FRIZZARINI, S. T.; NOGUEIRA, C. M. I. Conhecimentos prévios dos alunos surdos fluentes em libras referentes à linguagem algébrica no ensino médio. Revista Educação Especial, Santa Maria, v. 27, n. 49, p. 373-390, 2014. Disponível em: <https://doi. org/10.5902/1984686X8717>. Acesso em: 16 maio 2018.

GALVÃO, C. M.; SAWADA, N. O.; TREVIZAN, M. A. Revisão sistemática: recurso que proporciona a incorporação das evidências na prática da enfermagem. Revista LatinoAmericana de Enfermagem, Ribeirão Preto, v. 12, n. 3, p. 549-556, 2004. Disponível em: <https://doi.org/10.1590/S0104-11692004000300014>. Acesso em: 16 maio 2018.

GESSER, A. LIBRAS? Que língua é essa?: crenças e preconceitos em torno da língua de sinais e da realidade surda. São Paulo: Parábola Editorial, 2009.

GIL, A. C. Métodos e técnicas de pesquisa social. 6. ed. São Paulo: Atlas, 2008.

GÓES, M. C. R. Linguagem, surdez e educação. 4. ed. Campinas: Autores Associados, 2012.

KIPPER, D.; OLIVEIRA, C. J.; THOMA, A. S. Práticas visuais com alunos surdos: o visual e o escrito nas aulas de matemática. Boletim GEPEM, Rio de Janeiro, n. 67, p. 4-14, 2015.

MATOS, S. N.; MENDES, E. G. Demandas de professores decorrentes da inclusão escolar. Revista Brasileira de Educação Especial, Marília, v. 21, n. 1, p. 9-22, 2015. Disponível em: <https://doi.org/10.1590/S1413-65382115000100002>. Acesso em: 16 maio 2018.

MOURA, A. Q. Educação matemática e crianças surdas: explorando possibilidades em um cenário para investigação. 2015. Dissertação (Mestrado em Educação Matemática) Universidade Estadual Paulista Júlio de Mesquita Filho, Rio Claro, 2015.

MOURA, M. C. Surdez e linguagem. In: LACERDA, C. B. F.; SANTOS, L. F. (Org.).

Tenho um aluno surdo e agora?: introdução à Libras e educação de surdos. São Carlos: EdUFSCAR, 2013. p. 13-26.

NOGUEIRA, C. M. I.; ANDRADE, D.; ZANQUETTA, M. E. M. T. As medidas de comprimento na educação de surdos. Educação Matemática em Revista, Juiz de Fora, v. 16, n. 33, p. 24-35, 2011. 
Dessbesel, R. S.; Silva, S. C. R.; Shimazaki, E. M.

OLIVEIRA, C. C. B.; MANZINI, E. J. Encaminhamento e perfil do público-alvo da educação especial de uma sala de recursos multifuncionais: estudo de caso. Revista Brasileira de Educação Especial, Marília, v. 22, n. 4, p. 559-576, 2016. Disponível em: < https:/ /doi.org/10.1590/s1413-65382216000400007>. Acesso em: 16 maio 2018.

PEIXOTO, J. Gestos, sinais e esquemas de aprendizes surdos na multiplicação. Revista

Latinoamericana de Investigación en Matemática Educativa, México, v. 18, n. 3, p. 359-386, 2015a.

PEIXOTO, J. L. B. Análise dos esquemas de surdos sinalizadores associados aos significados da divisão. 2015. Tese. (Doutorado em Difusão de Conhecimento) Universidade Federal da Bahia, Salvador, 2015b.

PEREIRA, P. V. A surdez no ambiente escolar: um estudo das representações sociais de professores de matemática, intérpretes e alunos. 2014. Dissertação (Mestrado Profissional em Matemática em Rede Nacional) - Universidade Federal do Mato Grosso do Sul, Campo Grande, 2014.

ROCHA, F. B. M. Ensinando geometria espacial para alunas surdas de uma escola pública de Belo Horizonte (MG): um estudo fundamentado na perspectiva histórico cultural. 2014. Dissertação (Mestrado Profissional em Educação Matemática) - Universidade Federal de Ouro Preto, Ouro Preto, 2014.

RODRIGUES, R. S.; GELLER, M. Alunos surdos dos anos iniciais do ensino fundamental e a construção do número. Interfaces da Educação, Paranaíba, v. 7, n. 19, p. 126-145, 2016.

SALES, E. R. A visualização no ensino de matemática: uma experiência com alunos surdos. 2013. Tese (Doutorado em Educação Matemática) - Universidade Estadual Paulista Júlio de Mesquita Filho, Rio Claro, 2013.

SALES, E. R.; PENTEADO, M. G.; MOURA, A. Q. A negociação de sinais em Libras como possibilidade de ensino e de aprendizagem de geometria. Bolema, Rio Claro, v. 29, n. 53, p. 1268-1286, 2015. Disponível em: <https://doi.org/10.1590/1980-4415v29n53a23>. Acesso em: 16 maio 2018.

SAMPAIO, R. F.; MANCINI, M. C. Estudos de revisão sistemática: um guia para síntese criteriosa da evidência científica. Revista Brasileira de Fisioterapia, São Carlos, v. 11, n. 1, p. 83-89, 2007. Disponível em: < http://dx.doi.org/10.1590/S1413-35552007000100013>. Acesso em: 16 maio 2018.

VYGOTSKY, L. S. A formação social da mente: o desenvolvimento dos processos psicológicos superiores. 6. ed. São Paulo: Martins Fontes, 1998.

VYGOTSKI, L. S. Obras escogidas V: fundamentos de defectologia. Madri: Visor, 1997.

Artigo recebido em 05/08/2017. Aceito em 19/12/2017.

Contato: Universidade Tecnológica Federal do Paraná, Avenida

Monteiro Lobato, s/n, Km 04, Ponta Grossa, PR, 84016-210, Brasil. 